\title{
A política de avaliação da aprendizagem no contexto de um Programa Federal
}

\section{Brasileiro}

\section{The learning assessment policy in the context of a Brazilian Federal Program}

\author{
Gersonita Cruz*, Luciane Garcia** \\ *Universidade do Minho, **Universidade Federal do Rio Grande do Norte
}

\begin{abstract}
Resumo
Apresentam-se resultados de estudo realizado na rede municipal de ensino de Natal, RN, Brasil, que analisou a influência do Plano de Ações Articuladas (PAR), nas práticas de avaliação da aprendizagem, entre 2007 e 2011. A abordagem metodológica foi qualitativa, recorrendo-se a entrevistas semiestruturadas com profissionais da Secretaria de Educação e a documentos. Os dados foram tratados através da análise de conteúdo. A pesquisa revelou que, apesar do PAR decorrer de uma política gerencial, visar o controle de resultados e a responsabilização dos sujeitos, o municipio selecionou e implementou ações condizentes com sua proposta de avaliação formativa, reafirmando as práticas locais.

Palavras chave: Plano de Ações Articuladas. Avaliação da aprendizagem. Políticas Públicas Educacionais.
\end{abstract}

\begin{abstract}
The text presents the results of a study carried out in the municipal school network of Natal/RN, Brazil, that analyzed the influence of the Articulated Actions Plan (AAP) on learning assessment practices, from 2007 to 2011 . The methodological approach was qualitative, using interviews with professionals from the Secretary of Education and documents. Data were processed using content and documentary analysis. The results show that, although the AAP runs from a management policy, aiming the results control, as well as the accountability, the municipality selected and implemented actions, according to its proposal of formative assessment, reaffirming the local practices.

Keywords: Articulated Actions Plan; Learning Assessment; Educational Public Policies.
\end{abstract}

\section{Contextualizando o PAR}

Este trabalho discute as implicações da implementação do Plano de Ações Articuladas (PAR), na avaliação da aprendizagem da Rede Municipal de Ensino de Natal, no período de 2007-2011. A pesquisa, de natureza qualitativa, recorreu à análise bibliográfica e documental, além de entrevistas semiestruturadas com profissionais deste órgão municipal. O PAR consiste em um dos programas governamentais decorrentes do Plano de Desenvolvimento da Educação (PDE) e do Plano de Metas Compromisso Todos pela Educação (PMCTE) (BRASIL, 2007a).

Segundo Saviani (2007), o PDE reuniu programas educacionais implementados no segundo Governo de Luiz Inácio Lula da Silva (2007-2010), e se propõe a dinamizar o regime de colaboração entre os entes federados. Cury (2006) explica que na Constituição Federal de 1988 (CF), optou-se por um federalismo cooperativo com regime de colaboração recíproca, descentralizado, em que os entes federados compartilham funções, repartem competências e atribuições legislativas o que exige entendimento mútuo e participação nas decisões.

Visando dinamizar essas relações, os entes federados foram convidados a aderir ao PMCTE e elaborar o seu PAR, como meio de definir ações a serem desenvolvidas em colaboração e melhorar a qualidade educacional (BRASIL , 2007b). Apesar de não terem participado da discussão das propostas, todos os estados e municípios brasileiros elaboraram esse plano com vigência de quatro anos.

O MEC caracteriza o PAR como um planejamento multidimensional, cuja implementação é coordenada pelas secretarias municipais e estaduais de educação. Possibilita uma análise da situação educacional do município e a definição de ações considerando quatro dimensões: gestão educacional, formação de profissionais da educação, práticas pedagógicas e avaliação e infraestrutura física e recursos pedagógicos (BrasiL, 2007b)

$\mathrm{O}$ alcance das ações desenvolvidas nessas dimensões seria aferido pelo incremento do Índice de Desenvolvimento da Educação Básica (Ideb) das redes de ensino (BRASIL, 2007b). O Ideb é considerado um indicador da qualidade educacional, que combina dados provenientes do rendimento e do fluxo escolar. Constitui-se em uma política gerencial que colabora, sobremaneira, para a responsabilização dos profissionais pelos resultados educacionais.

Esse trabalho se limitou a analisar a implementação das ações referentes à dimensão de Prática pedagógica e avaliação, área 2, cujas ações são descritas no ítem seguinte.

Ações de avaliação da aprendizagem promovidas pelo PAR na rede municipal de ensino de Natal

A Área 2, “Avaliação da Aprendizagem dos Alunos e Tempo para Assistência individual/coletiva aos alunos que apresentam dificuldade de aprendizagem", é composta por três indicadores: 1) formas de avaliação da 
aprendizagem dos alunos; 2) utilização do tempo para assistência individual/coletiva aos alunos que apresentavam dificuldades de aprendizagem; e 3) política específica de correção de fluxo (BRASIL, 2007c).

Considerando a realidade das escolas, uma comissão composta, principalmente, por profissionais da Secretaria Municipal de Educação definiu, para cada indicador, uma ação para ser implementada. Conforme o PAR do Município de Natal (BRASIL, 2007c), no que se referiu ao indicador 1 , a rede de ensino se propôs a "Incluir como componente da política educacional o estímulo à autoavaliação e às práticas interdisciplinares", de forma que essa ação se desdobrou em uma subação. O segundo indicador, que se refere à assistência aos alunos com dificuldades de aprendizagem, gerou a ação: "Orientar as escolas a incluírem no projeto pedagógico a oferta do tempo para assistência individual e/ou coletiva aos alunos que apresentam dificuldade de aprendizagem durante $\mathrm{o}$ ano letivo $\mathrm{e}$ tempo de atendimento educacional". Essa ação gerou outras 3 subações. Por fim, o terceiro indicador referente à correção de fluxo, gerou a ação: Implementar políticas para correção de fluxo, que originou 2 subações (BRASIL, 2007c).

Assim, ao todo, foram geradas seis subações, cuja implementação estava sob a incumbência municipal. Além dessas, apenas o Indicador referente à política de correção de fluxo, gerou uma subação que contou com a Assistência Técnica do MEC (BRASIL, 2007c). Esse indicador refere-se ao desenvolvimento de programa de correção de fluxo, para reverter situação de fracasso escolar, que, historicamente, constitui-se em problema recorrente na educação brasileira e que afeta os resultados do Ideb. Não foi prevista assistência financeira do MEC para nenhuma subação da área, ficando a maior incidência de ações sob a responsabilidade municipal.

\section{Analisando a implementação das ações de avaliação da aprendizagem do PAR de Natal/RN}

O PAR do Município de Natal (BRASIL, 2007c) demonstra a preocupação da rede de ensino com a aprendizagem dos estudantes, mas também, com os resultados do Ideb, que, no período em apreço, foi considerado crítico. Isso justifica a implementação de ações de avaliação da aprendizagem bem como a atenção prestada aos estudantes que demandam maior tempo e investimentos para aprender. Ações desse tipo visam à correção do fluxo escolar, evitando casos de evasão e de repetência.

Conforme informação das Assessoras da SME, informantes da pesquisa, embora a maioria das ações de avaliação da aprendizagem tenham ficado sob responsabilidade municipal, este nem sempre garantiu as condições necessárias à efetivação do compromisso assumido. Algumas não tiveram continuidade devido à mudanças na gestão municipal e na SME, além disso, observou-se falta de articulação entre os setores da Secretaria e de monitoramento das ações. Embora determinadas ações do PAR estivessem, de alguma forma, sendo desenvolvidas, as assessoras entrevistadas não as relacionavam a esse plano.
Uma vez que, no PAR de Natal, apenas um indicador da área de avaliação da aprendizagem gerou ação, que contou com apoio técnico do MEC, questiona-se a efetividade da colaboração promovida nessa área. Isso porque entende-se que o regime de colaboração vai além da adesão à políticas definidas sem a participação dos entes federados, do fomento ao planejamento de ações e do monitoramento dos resultados finais do processo educativo.

Apesar disso, a assistência do MEC na execução dessa única ação foi fundamental para ampliar a capacidade do município de atender às demandas dos estudantes. Apesar de ter iniciado com atraso, efetivou-se a contento a formação continuada de professores e assessoria técnica para implementação do programa de correção de fluxo escolar.

Conforme a Assessora A (2014), desde 2001, antes da elaboração do PAR, já se buscava vivenciar na rede municipal a concepção de ciclos de aprendizagem e de avaliação formativa, conforme a regulamentação da Resolução 01/2001 (NATAL, 2001). Para essa Assessora (2014), compreende-se que nessa rede de ensino, a avaliação deve ser "[...] diagnóstica, cumulativa, inclusiva e redimensionadora da ação pedagógica, no sentido de ultrapassar a visão classificatória”. Dessa forma, orienta-se as escolas a avaliarem os estudantes "[...] de acordo com o nível em que se encontram e não de forma homogénea, [...] a respeitar as diferenças de ritmos e de desenvolvimento do aluno, incentivando-o a ter confiança em sua capacidade de aprender" (Assessora A, 2014).

Apesar dessas orientações, a Assessora A (2014), considera que práticas desse tipo não se encontram consolidadas em todas as escolas. Faltam condições necessárias a essa implementação no cotidiano escolar, havendo, inclusive, resistência de determinados professores, a despeito do trabalho desenvolvido pela assessoria pedagógica.

A finalidade da avaliação formativa, segundo Gil (2006), é proporcionar informações atinentes ao processo de ensino-aprendizagem, para que o professor ajuste a prática educativa conforme as características do aluno, orientando-o, apoiando-o e corrigindo-o quando necessário. Esse tipo de concepção de avaliação, demandou atenção da rede de ensino na escolha do programa de assistência técnica do MEC que seria implantado no âmbito municipal. Entre as opções existentes, a Assessora C (2014) assevera que "[...] pelo próprio PAR conseguimos o Grupo de Estudos sobre Educação Metodologia de Pesquisa e Ação (GEEMPA) que trabalha com a correção de fluxo, pois o Sistema de Ciclo trabalhava apenas com algumas escolas e não estava estendido a todos. Com o GEEMPA ampliou mais, pois tinha os dias certos de atividades no contraturno",

A SME optou pelo programa do Grupo de Estudos sobre Educação Metodologia de Pesquisa e Ação (GEEMPA), visto que já havia desenvolvido trabalhos anteriormente com esse grupo e acreditava na proposta oferecida. A Assessora D, no entanto, destaca que o "[...] programa só veio iniciar em 2010, então, desde esse ano, o município de Natal o executa e temos obtido resultados 
muito positivos". Dessa forma, as ações de correção de fluxo escolar promovidas colaboraram para fortalecer a concepção avaliativa da rede de ensino, colaborando para consolidação da avaliação formativa na rede.

\section{Considerações finais}

O Plano de Ações Articuladas tem como propósito dinamizar as ações de colaboração entre os entes federados, na promoção de serviços educacionais. Esse plano é único para todo o país e foi concebido sem a participação dos entes federados. Uma vez que o MEC condicionou seu apoio técnico e financeiro à adesão ao PMCTE e à elaboração do PAR, ele tornou-se quase uma imposição às redes de ensino, em particular, ao Município de Natal.

Apesar disso, nessa rede de ensino já existiam concepções educativas e avaliativas próprias. A partir do PAR foram programadas ações de estímulo à autoavaliação, assistência aos alunos com dificuldade de aprendizagem e que visavam a correção de fluxo escolar as quais promoveram uma sistemática de ações adequadas à realidade do município. Considera-se, no entanto, que a assistência técnica do MEC colaborou para fortalecer as concepções locais.

O PAR constitui-se em uma política gerencial, que se pauta em uma concepção de avaliação baseada no ranqueamento das instituições com base nos resultados obtidos, tendo em vista o controle sobre os resultados e a responsabilização dos sujeitos. Porém, ao disponibilizar diferentes opções de programa para as ações referentes à avaliação da aprendizagem, o Município de Natal pôde optar por um que reforçou suas próprias concepções.

\section{Referências}

Assessora a. Entrevista concedida a gersonita paulino de sousa cruz. Natal, 4 de nov. 2014.

Assessora c. Entrevista concedida a gersonita paulino de sousa cruz. Natal, 19 de nov. 2014.

Assessora d. Entrevista concedida a gersonita paulino de sousa cruz. Natal, 21de nov. 2014.

Brasil. Ministério da educação. O plano de desenvolvimento da educação: razões, princípios e programas. Brasília: mec, 2007a.

Brasil. Decreto n. 6.094 de 24 de abril de 2007. Dispõe sobre a implementação do plano de metas compromisso todos pela educação e dá outras providências. Presidência da república: casa civil, 2007b.

Brasil, Ministério da Educação. Sistema integrado de monitoramento do ministério da educação, secretaria executiva. Plano de ações articuladas - par natal (2007-2011). 2007c. Documento impresso, disponibilizado pelo departamento de assessoria de planejamento (apa). Secretaria municipal de natal/rn. Acesso em: 2014.

Cury, Carlos Roberto Jamil. Federalismo político e educacional. En: Ferreira, Nauras y Riacarapeto (orgs.). Políticas públicas e gestão da educação. Brasília: Líber Livro, 2006.

Gil, Antonio Carlos. Didática do ensino superior. São Paulo: Atlas, 2006.
Natal. Resolução n. 001/01 - cme. Estabelece normas para o sistema de ensino do município do natal, emobservânciaàsdisposições da lei 9.394, de 20 de dezembro de 1996 - diretrizes e bases da educação nacional. Prefeitura municipal. Secretaria municipal de educação de natal. Conselho municipal da educação, 2001.

Saviani, Dermeval. O plano de desenvolvimento da educação: análise do plano mec. Educação \& sociedade, campinas, v. 28, n. 100, out. 2007. 